\title{
Evaluation of Social Capital, Considering Sociability and Walkability in Urban Fabrics: The Case of Isfahan City, Iran
}

\author{
Mohamad Masoud \\ Assistant professor at Art University of Isfahan, Isfahan, Iran
}

Sajed Rastbin

Master student in urban design at Art University of Isfahan, Isfahan, Iran

Fateme Tohidy Ardahaey (Corresponding author)

PhD student, Department of Cultural Management and Planning

Faculty of Management and Economics, Science and Research Branch

Islamic Azad University, Tehran, Iran

E-mail: ftohidy@yahoo.com

\author{
Received: May 16, $2011 \quad$ Accepted: May 30, $2011 \quad$ Published: October 1, 2011 \\ doi:10.5539/ass.v7n10p216 URL: http://dx.doi.org/10.5539/ass.v7n10p216
}

\begin{abstract}
Social capital as prominent branch of sociology and social science is recently considered -though as a conceptual tool- in the field of urban design to improve urban qualities. In this study, considering that promotion of social functions in urban texture is a strategy to increase quality of citizenship life, it is tried to find some logical relationships between the level of the social capital and walkability and sociability as the qualities of urban design within social context, in order to be able to enhance social capital substrates and provide an urbanism approach to develop an operational tool the concept of social capital in urban design. This article tries to study the effects of urban qualities including walkability and sociability on the level of social capital in a community. In this respect, after offering some common definition for the concept of social science from the viewpoints of some experts in this field, and dealing briefly with the notions of walkability and sociability, the evaluation of each quality as well as its sub-qualities based on AHP technique are presented. The results from the statistical and quantified analysis of the data from questionnaires showed that there is a direct relationship between changes in the qualities and the social capital indicators; however, this relationship is not a linear one.
\end{abstract}

Keywords: Social capital, Urban qualities, Quantifying, Sociability, Pedestrian, Walkability

\section{Introduction}

Urban design is a technique and knowledge seeking to organize and improve urban qualities and increase the quality of citizenship life. Based on the perspectives and objectives of urban design, the dominant intention in all urbanism activities is to reach high humanistic and social dimensions. In fact, what give meaning to a city are the social aspects raised in recent urban activities, in addition to the physical and visual body of it. In recent researches conducted in the field of urban design, social qualities in conjunction visual, functional and spatial qualities are emphasized. In this study, based on extensive studies regarding urban qualities, social qualities as well as social capital are focused on as the parameter influenced by social relationships which is lost in most urban designs. According to the conceptual definitions of social capital, its promotion in urban contexts would not be achieved unless applying some changes to enhance the urban qualities in connection to it. Urban qualities as a tool for urban planners to promote and organize the environment have the ability to provide substrates for shaping and promoting the social capital. To understand the relationship between the social capital and the urban qualities associated with it, it is necessary to evaluate and analyze the level of changes in urban qualities and social capital. Before offering the analyses in this study, considering the various factors and urban qualities affecting the social capital, the concepts of social capital and urban qualities are briefly dealt with. 


\subsection{The concept of social capital}

Social capital (SC) is an over and often inappropriately used concept, and is ill defined. Journal articles are increasingly appearing about the concept, whole books and a number of literature reviews are even being written on the ever-fashionable term (Adler \& Kwon 2002, Woolcock 1998). Indeed a SC 'google' search returns over two million sites, with the concept being used to explain everything from lower levels of crime to better health (Aldridge, Halpern \& Fitzpatrick 2002). Furthermore, SC is increasingly cited in political circles (Portes \& Landolt 1996) as a justification for less state involvement, espousing the argument that greater responsibility should be given to the community (Szretzer 2002, Giddens 2000, Fine 1999). There are three quite widely acknowledged (Fine 1999, Adler \& Kwon 2002, Woolcock 1998) problems of the literature on SC: 1) there are problems surrounding the definition of the concept 2) it is considered to be a chaotic concept7 3) many authors believe that it neglects issues of power and conflict (Kulynych \& Smith 2002, Fine 1999:16). This section attempts to reconcile these problems. The disparate conceptualization of the term can be seen in Table 1 .

From this growing literature, a number of themes can be identified in the definition of SC. The first is participation in networks: the notion of dense inter-locking networks of relationships between a variety of actors (Burt 2000, Lin 1999). The second is reciprocity: the notion of short-term altruism and long-term self interest an actor may act for the benefit of others at a personal cost, with the general expectation that this kindness will be returned at some undefined point in time. Otherwise referred to as the 'favor bank', Elster (1989) gives the simplistic example of present giving. The third is trust: this entails a willingness to take risks in a social context based on a sense of confidence that others will act as expected and in mutually supportive ways (at a minimum that others do not intend harm) (Fukuyama 1995, Elster 1989) The fourth theme is the institutional setting (norms, taboos, etcetera): they provide a form of informal social control that precludes the necessity for formal institutions (Knack \& Keefer 1997). The fifth is the stock or commons: networks, reciprocity, trust, and the institutional setting combine to form a strong community, with shared ownership over the SC. Finally, the sixth, pro-activity, is implicit in earlier themes, that is, a sense of individual and collective worth requires the active and willing engagement of citizens within a participative community. SC is not located in the individual actor or within the social structure, but in the space between (Coleman 1988). It is not the property of organizations, the market, or the state, though all can engage in its production. Inherent in the concept, is the notion of people as creators.

Where sociability, walkability and all their components illustrated in figure 1 are high in a society, one could expect a high social capital as well among its members.

It is also argued that government officials and thus government policies will have greater credibility in societies with higher levels of SC. So, the main concern of this article is to review the effect of the two qualities of sociability and walkability on social capital.

\subsection{Walkability and Pedestrian Flow}

Until the Second World War, pedestrian facilities in the form of sidewalks, paths, and crosswalks normally accompanied the development of residential and commercial areas in both urban and suburban districts. Since then, the importance of these facilities diminished as automobile use became widespread (Moudon et al., 1996). Current problems of traffic congestion, air pollution, and oil dependence have led local and national decision makers to enact legislation and policies aimed at increasing transit use and vehicle occupancies. Enhancing the use of non-motorized transport as an alternative to single-occupant vehicles has also become a priority item in transportation policy (Moudon et al., 1996). Planning policy and practice aspires to develop a normative definition of a "walkable" environment and there have been a number of efforts to test these definitions empirically (Ewing, 1999; Partnership for a Walkable America, 2001; Targa and Clifton, 2005). Most studies concerned with walking behavior evaluate the environmental attributes by their degree of accommodation for pedestrians and the correlations with levels of walking (Aultman-Hall et al., 1997; Greenwald and Boarnet, 2001).

A variety of measures have been used to represent the built environment in studies of land use and travel behavior. In a study by Berrigan and Troiano (2002), a simple measure of neighborhood age is used as a proxy of walkability. Crane (1996) used three variables to describe the local environment: population density, land use mix and street pattern. And, a more comprehensive array was used by Craig et al. (2002), where 18 environmental measures described characteristics of destinations, aesthetics, and traffic. However, the research has thus far been unable to establish a definitive characterization of the elements that comprise a walkable environment or are influential in affecting rates of pedestrian activity (Crane, 2000; Vernez-Moudon and Lee, 2003). The lack of micro scale environmental data has been a limitation but the collection of detailed 
information about non-motorized activity has been overlooked in many transportation studies, further hampering these efforts.

Also, many studies concerned with walking behavior evaluate the environmental attributes by their degree of accommodation for pedestrians and the correlations with levels of walking (Aultman-Hall et al., 1997; Greenwald and Boarnet, 2001). Considering this issue and making efforts to improve the quality of walkable environment in neighborhoods as it is shown in the results of the present study would lead to increase in the social capital among a society.

\subsection{Urban Sociability}

Urban sociability is difficult to quantify - even define - but nevertheless represents the sum part of everyday patterns of life, comings and goings, memories and associations of places and qualities such as friendliness, civility and good manners. Urban sociability exists where communities of people identify, broadly speaking, with one another and with the place in which they live. This means that urban sociability is a combination of robust communities, good places - neighborhoods, districts, suburbs, free-standing towns - and forms of social life that occur in public places. In turn, this means that in order to comprehend urban sociability, and to see its strengthening as a realistic policy objective, we need to first understand how theories of community, place and public social life might be combined. These clearly over-lap in the real world, but in the theory there are many overlaps and conjunctions that remain to be explained. At its simplest, urban sociability is the playing out of community norms and values in the places where people live. Where urban sociability exists, we can posit, community life and the sense of place and local identity will tend to be stronger. More than this, it seems likely that a healthy balance of community, place identity, a well-liked public realm and public social life will produce a whole that is greater than the sum of its parts. Urban sociability is an example of gestaldt (Montgomery, 2006).

Franco Bianchini has also argued that 'public social life' is "the interacting of socializing or sociability that occurs within the public realm" (Bianchini, 1990). The concept of public social life is a much wider concept than the public spaces or places in the city, but refers rather to a distinctive set of social relations. The attraction of the city is that it liberates individuals from deeply felt norms in the private self, and allows people to learn about themselves and others (Montgomery, 2006).

\section{Research Method}

Based on the nature of the research and social dimensions discussed, the network of the nodes in an urban area and the passes connecting them could be considered as an appropriate network for evaluation and comparison of levels of social capital indicators with the change rate in the urban quality and also for studying the relationship between them. Social nodes are some marked points recorded as mental images in people's minds which entail behavioral characteristics of behavioral settings. Social nodes were initially identified and recorded based on field observations and in the next stage, to ensure the accuracy of field observations and results obtained from it, the technique of distributing questionnaires was used. Analysis of the results obtained from the questionnaires tried to review the exact location of neighborhood nodes in people's mind, their preferences and expectations from the nodes and to study the original estimations of the urban quality.

\subsection{Quantifying the Urban Qualities}

Quality concepts of urban design due to their inherent quality characteristics cannot be compared with quantitative results obtained from the questionnaires and thus, they need to convert to quantitative data as far as possible. To quantify urban qualities, one needs to identify the factors and sub-qualities contributing in each quality so as to determine and calculate mathematical and quantity concepts of them. Determination of the sub-qualities of such qualities as sociability and walkability has been conducted based on the review of the extent of the subject literature.

To evaluate the sub-qualities and estimate the final result for each quality, some mathematical and engineering techniques were applied including: FUZZY techniques, Multiple Criteria Decision Making (MCDM), Analytical Hierarchy Process (AHP) and Analytical Network Process (ANP). In this study, AHP technique due to the nature of specified qualities and sub-qualities and also because of the simplicity, flexibility and the possibility of using quantitative and qualitative criteria simultaneously in this technique has been chosen for determining weights of sub-qualities. The first step in AHP is building a hierarchical structure of the subject along with goals, standards, options and connection between them. Since the above technique is used as a subsidiary tool for achieving the ultimate goal of the study, it seems not necessary to offer the existing mathematical relationship and the way to form binary matrix decision making and instead, the software of Expert Choice has been applied. The above-mentioned software is fully based on the AHP technique and determines the factors of decision making 
(urban design qualities in this study) and binary compares factors of decision making based on expert's opinion and determines sub-factors of each factor (sub-qualities of each quality in this study). Also, the binary comparison of sub-factors of each factor was based on the expert's opinion. The result of the process and determination of weights (priority scheme) of sub-factors will be based on the research goal. Table 2 offers sub-qualities determined for each quality and calculated weights for sub-qualities based on AHP as well as the evaluation and quantification method for each of them.

This study compared the evaluation of qualities of walkability and sociability rather than focusing separately on each of them. This is because the sub-qualities specified for each above-mentioned quality are not capable to identify separately the factors affecting the social capital. In other word, all sub-qualities of the mentioned qualities affect complementarily the social capital and thus the evaluation of the effect of both qualities on social capital is compared in this study.

\subsection{Analysis of Results from Questionnaires for Setting Level of Social Capital}

After picking initial questionnaires and reviewing them in terms of clarity and straightforwardness and the capability of questions to convey the desired concept, the number of questions and their writing style from the viewpoint of respondents, the questionnaires were standardized according to the statistical indicators (statistical population, scattering rate of preliminary results obtained and percentage of expected reliability) and were distributed among a certain number of people in the neighborhood (334 people in this study.) Analysis of the results obtained from these questionnaires was used to review the level of social capital in social nodes and links connecting them in the studied domain.

\subsection{Research Sample}

As mentioned before, based on the nature of the study, a network consisting of social nodes and passes connecting them has been developed in Jolfa district in Isfahan. Nodes were initially picked based on observations and the field of study was picked at different times based on the analysis of the results from questionnaires and also analysis of mental images of people. The graph obtained in the study sample comprised 87 nodes and 154 edges. Map 1 illustrates the position of social ties and the links connecting them in Jolfa district of Isfahan.

Since the number of nodes and the links connecting them is large in the present study, the analytical results for a limited number of them will be provided as samples. As noted, the evaluation of sub-qualities for qualities of walkability and sociability would be considered as the base of comparison in assessing the level of social capital. Table 3 offers the analysis results and quantification of walkability and sociability in a number of nodes and links. Also, map 2, 3, and 4 illustrate graphically the final results from the calculation of walkability and sociability and their resultant in Jolfa district of Isfahan.

Determining weights of factors contributing in social capital as well as the weight of qualities and sub-qualities of has been conducted using AHP technique. Results from the calculation of levels of social capital are offered in a limited number of nodes and links as the sample. Table 4 shows the results from the evaluation of the level of social capital in a number of nodes and links in the studied region and the final results from the calculation of the level of social capital in nodes and links of the district are illustrated in the map 5.

\section{Results}

\subsection{Relationship between Social Capital and Qualities of Walkability and Sociability}

Comparison of data obtained from analysis of questionnaires to assess the level of social capital as well as the results from the analysis of qualities of walkability and sociability obtained from urban design analysis techniques indicated that there is a direct and positive relationship between the changes in qualities of walkability and sociability and the social capital. The results from the study showed that although there is a direct relationship between changes in the studied qualities and the social capital indicators, but this relationship is not a linear one.

Table 5 shows the final resultant from evaluation of walkability and sociability and social capital in the nodes of the studied region and the evaluation of the above variables in the links of the region are shown in table 6 . Figure 1 and 2 display the comparison of the results from calculation of qualities of walkability and sociability and the social capital in the nodes and links of the studied region. Figure 3 as the conceptual model of the research illustrates how urban qualities (and sub-qualities) affect the social capital. 


\section{Conclusion}

Studying the concept of social capital, its various definitions and all factors involved in it show the existence of multiple factors with complex relationships that influence the concept, studying and fully understanding and determining the impact of which seems very difficult. Each of the definitions of social capital has focused on a particular aspect of it which deals with some different operational definitions of the concept. Most recent research concerning the impact of social and human factors on social capital, including age, gender, level of wealth, education, etc, has been conducted and agreements on certain conceptual and operational definitions have been obtained, based on which this study tried to determine the level of social capital.

Given that the concept of networks in social capital is of basic concepts and its emergence and strengthening in urban public spaces demand enhancing specific urban qualities, this study reviewed and evaluated changes in the social capital considering urban qualities such as walkability and sociability. As mentioned in the literature of the study, there are various factors influencing social capital which influenced one another in a complex way. The qualities considered in this study are only some samples of urban qualities which affect social capital. In fact, the purpose of this study more social aspects of urban design and this study aims to find some simplified relationships between urban qualities and social concepts including social capital.

The results from this study proved the existence of a direct relationship between qualities of walkability and sociability and social capital. It was also indicated that the relationships between the urban qualities and social capital are nonlinear. This is because social capital can be influenced by many other factors each of which has different impact in studied domains.

\section{References}

Adler, Paul, and Seok-Woo Kwon. (2002). Social capital: prospects for a new concept. Academy of Management Review, 27(1): 17-40. http://dx.doi.org/10.5465/AMR.2002.5922314

Aldridge, Stephen, David Halpern \& Sarah Fitzpatrick. (2002). Social capital: a discussion paper. Performance and Innovation Unit. [Online] Available: www.cabinetoffice.gov.uk/innovation/2001/futures/socialcapital.pdf (6 May 2002).

Aultman-Hall, L., Roorda, M., \& Baetz, B. (1997). Using GIS for evaluation of neighborhood pedestrian activity. J. Urban Plan. Dev.

Berrigan, D., \& Troiano, P. (2002). The association between urban form and physical activity in U.S. adults. Am. J. Prev. Med., 23 (2S).

Bianchini, F. (1990). op cit.

Burt, Ronald. (2000). The network structure of social capital. Research in Organization Behavior, 22.

Coleman, James. (1988). Social capital in the creation of human capital. American Journal of Sociology, 94.

Craig, C.L., Brownson, R.C., Cragg, S.E., \& Dunn, A.L. (2002). Exploring the effect of the environmental on physical activity: a study examining walking to work. Am. J. Prev. Med., 23 (2S).

Crane, R. (1996). On form versus function: will the new urbanism reduce traffic, or increase it? J. Plan. Educ. Res., 15, 117-126.

Crane, R. (2000). The influence of urban form on travel: an interpretive review. J. Plan. Lit., 15(1). http://dx.doi.org/10.1177/08854120022092890

Elster, Jon. (1989). Social norms and economic theory. Journal of Economic Perspectives, 3.

Ewing, R. (1999). Pedestrian and Transit-friendly Design: a Primer for Smart Growth. ICMA, Washington, DC.

Fine, Ben. (1999). The developmental state is dead - long live social capital. Development and Change, 30(1).

Fukuyama, Francis. (1995). Trust, the social virtues and creation of prosperity. New York: The Free Press Paperbacks.

Giddens, Anthony. (2000). The third way and its critics. Cambridge: Polity Press.

Greenwald, Michael J., Boarnet, \& Marlon G. (2001). The built environment as a determinant of walking behavior: analyzing non-work pedestrian travel in Portland, Oregon. Transportation Res. Rec., 1780, 33-43.

Knack, Stephen, and Philip Keefer. (1997). Does social capital have an economic payoff? A cross-country investigation. Quarterly Journal of Economics, 112(4). http://dx.doi.org/10.1162/003355300555475 
Kulynych, Jessica, and Stephen Samuel Smith. (2002). It may be social, but why is it capital? The social construction of social capital and the politics of language. Politics and society, 30(1).

Lin, Nan. (1999). Social networks and status attainment. Annual Review of Sociology, 25.

Montgomery J. (2006). Community Strengthening through Urban Sociability. Department for Victorian Communities, Urban Cultures Ltd.

Moudon A. V., Hess P. M., Snyder M. C., \& Stanilov K. (1996). Effects of Site Design on Pedestrian Travel in Mixed-Use, Medium-Density Environments. Transportation Research Record, 1578, Paper No. 971360.

Partnership for a Walkable America. (October, 2001). Walkable America Checklist. [Online] Available: http://www.nsc.org/walkable.htm.

Portes, Alejandro \& Patricia Landolt. (1996). The Downside of Social Capital. The American Prospect, 26:18-21.

Szretzer, Simon. (2002). The state of social capital: bringing back in power, politics, and history. Theory and Society, 31.

Targa, F., \& Clifton, K.J. (2005). The built environment and trip generation for non-motorized travel. $J$. Transportation Stat., 8(3): 55-70.

Vernez-Moudon, A., \& Lee, C. (2003). Walking and bicycling: an evaluation of environmental audit instruments. Am. J. Health Promot., 18(1).

Woolcock, Michael. (1998). Social capital and economic development: toward a theoretical synthesis and policy framework. Theory and Society, 27:151-208. http://dx.doi.org/10.1023/A:1006884930135

Table 1. The disparate nature of the social capital definition: some selected definitions

\begin{tabular}{|c|l|}
\hline Author & \multicolumn{1}{|c|}{ Definition } \\
\hline Hanifan (1916:130) & $\begin{array}{l}\text { 'Those tangible assets [that] count for most in the daily lives of people namely good } \\
\text { will, fellowship, sympathy, and social intercourse among the individuals and families } \\
\text { who make up a social unit'. }\end{array}$ \\
\hline Jacobs (1961:138) & 'Networks...'. \\
\hline Bourdieu (1986:248) & $\begin{array}{l}\text { 'the aggregate of the actual or potential resources which are linked to possession of a } \\
\text { durable network of more or less institutionalized relationships of mutual acquaintance } \\
\text { and recognition' } \\
\text { (1986:243) 'made up of social obligations ('connections'), which is convertible, in } \\
\text { certain conditions, into economic capital and may be institutionalized in the form of a } \\
\text { title of nobility'. }\end{array}$ \\
\hline Coleman (1990:302) & $\begin{array}{l}\text { 'Defined by its function. It is not a single entity, but a variety of different entities } \\
\text { having two characteristics in common. They all consist of some aspect of social } \\
\text { structure, and they facilitate certain actions of individuals who are within the } \\
\text { structure'. }\end{array}$ \\
\hline Schiff (1992:160) & $\begin{array}{l}\text { 'The set of elements of the social structure that affects relations among people and are } \\
\text { inputs or arguments of the production and/or utility function'. }\end{array}$ \\
\hline Putnam (1995:664) & $\begin{array}{l}\text { 'features of social life - networks, norms, and trust - that enable participants to act } \\
\text { together more effectively to pursue shared objectives...Social capital, in short, refers } \\
\text { to social connections and the attendant norms and trust'. }\end{array}$ \\
\hline Fukuyama (1995:10) & $\begin{array}{l}\text { 'The ability of people to work together for common purposes in groups and } \\
\text { organizations'. } \\
\text { (1999:16) 'a set of informal values or norms shared among members of a group that } \\
\text { permit cooperation among them'. } \\
\text { (2000:3) 'an instantiated informal norm that promotes cooperation between two or } \\
\text { more individuals'. }\end{array}$ \\
\hline Knack \& Keefer (1997:1251) & 'Trust, cooperative norms, and associations within groups'. \\
\hline & \multicolumn{2}{|c|}{} \\
\hline
\end{tabular}




\begin{tabular}{|c|l|}
\hline Woolcock (1998:155) & $\begin{array}{l}\text { 'the norms and networks facilitating collective action for mutual benefit' (1998:186) } \\
\text { '(i) within their local communities; (ii) between local communities and groups with } \\
\text { external and more extensive social connections to civil society; (iii) between civil } \\
\text { society and macro-level institutions; and (iv) within corporate sector institutions'. }\end{array}$ \\
\hline Lin (1999:471) & $\begin{array}{l}\text { 'Resources accessed in social networks...focuses on the instrumental utility of such } \\
\text { resources'. }\end{array}$ \\
\hline Gargiulo \& Benassi (1999:299) & $\begin{array}{l}\text { 'Networks [that] facilitate access to information, resources, and opportunities...' that } \\
\text { 'help actors to coordinate critical task interdependencies and to overcome the } \\
\text { dilemmas of collective action'. }\end{array}$ \\
\hline $\begin{array}{c}\text { Serageldin \& Grootaert } \\
\text { (2000:44 \& 46) }\end{array}$ & $\begin{array}{l}\text { the 'certain degree of common cultural identifications, a sense of 'belonging' and } \\
\text { shared behavioral norms' 'the social and political }\end{array}$ \\
\hline
\end{tabular}

Table 2. Sub-qualities of Each Quality and Evaluation of Sub-qualities and Calculated Weights for Each Based on AHP (A: Field Observation, B: Map of Selected District, C: Questionnaire)

\begin{tabular}{|c|c|c|c|}
\hline Quality & Sub-quality & $\begin{array}{l}\text { Evaluation } \\
\text { Method }\end{array}$ & $\begin{array}{c}\text { Weight } \\
\text { (Based on } \\
\text { AHP) }\end{array}$ \\
\hline \multirow{5}{*}{ sociability } & $\begin{array}{l}\text { 1-Evaluate Attractive Land-Use Based on Sum of Population } \\
\text { Attraction Considering Age and Sex }\end{array}$ & A,B & 0.193 \\
\hline & 2- Evaluate Adaptability of Mixed-Use & $\mathrm{A}, \mathrm{B}$ & 0.133 \\
\hline & 3- Evaluate Sociable Urban Furniture & A & 0.159 \\
\hline & 4- Evaluate Designed and Sociable Urban Places & A & 0.281 \\
\hline & 5- Evaluate Climatic Comfort & A & $\mathbf{0 . 2 3 4}$ \\
\hline \multirow{7}{*}{ walkability } & 1- Evaluate Pedestrian Attractive Activities & $\mathrm{A}, \mathrm{B}$ & 0.145 \\
\hline & 2- Evaluate Pedestrian Safety & $\mathrm{A}, \mathrm{B}$ & $\mathbf{0 . 1 2 0}$ \\
\hline & 3- Evaluate Intersection of Pedestrian and Automobile Paths & $\mathrm{A}, \mathrm{B}$ & 0.142 \\
\hline & $\begin{array}{l}\text { 4- Evaluate Pavement for Pedestrian Guidance and Movement } \\
\text { Convenience }\end{array}$ & A & $\mathbf{0 . 0 7 0}$ \\
\hline & $\begin{array}{l}\text { 5- Evaluate Volume of Pedestrian Flow Based on Primary and } \\
\text { Secondary Activities }\end{array}$ & $\mathrm{A}, \mathrm{B}$ & 0.224 \\
\hline & 6- Evaluate Useful Width of Pedestrian Paths & $\mathrm{A}, \mathrm{B}$ & 0.120 \\
\hline & 7- Evaluate Level of Service in Pedestrian Paths & $\mathrm{A}, \mathrm{B}$ & 0.179 \\
\hline \multirow{9}{*}{ Social Capital } & 1-Trust & $\mathrm{C}$ & 0.108 \\
\hline & 2-Network & $\mathrm{C}$ & 0.220 \\
\hline & 3- Assistance & $\mathrm{C}$ & 0.098 \\
\hline & 4- Cooperation & $\mathrm{C}$ & 0.098 \\
\hline & 5- Capacity to Accept Differences & $\mathrm{C}$ & 0.125 \\
\hline & 6- Influence Feeling in Life & $\mathrm{C}$ & 0.079 \\
\hline & 7- Social Mediation & $\mathrm{C}$ & 0.079 \\
\hline & 8- Social Support & $\mathrm{C}$ & 0.079 \\
\hline & 9- Social Involvement & $\mathrm{C}$ & 0.114 \\
\hline
\end{tabular}


Table 3. Analysis results and quantification of walkability and sociability in a number of nodes and links In Jolfa district

Sociability Quality

Walkability Quality

\begin{tabular}{|c|c|c|c|c|c|c|c|c|c|c|c|c|c|c|c|c|c|c|}
\hline IMPORTANCE & 0.193 & 0.133 & 0.159 & 0.281 & 0.234 & & & 0.145 & 0.12 & 0.142 & 0.07 & 0.224 & 0.12 & 0.179 & & & \multicolumn{2}{|c|}{ Resultant } \\
\hline 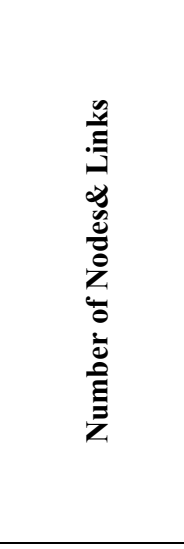 & 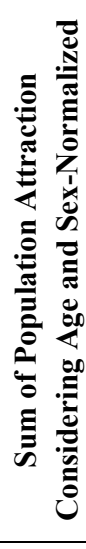 & 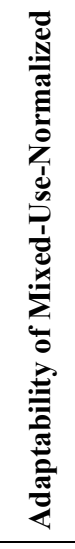 & 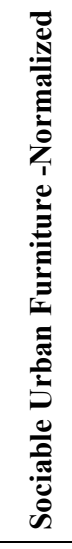 & 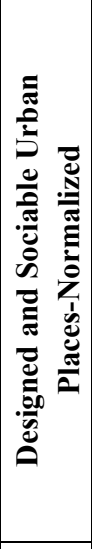 & 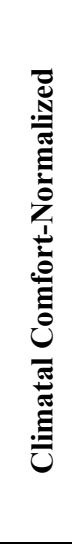 & 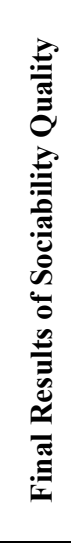 & 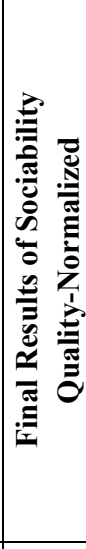 & 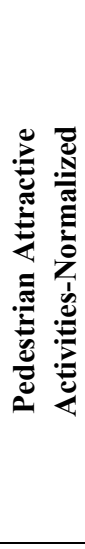 & 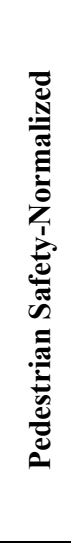 & 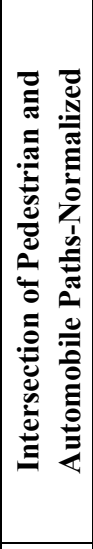 & 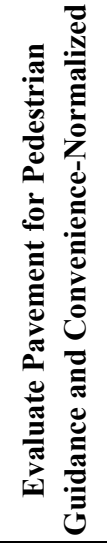 & 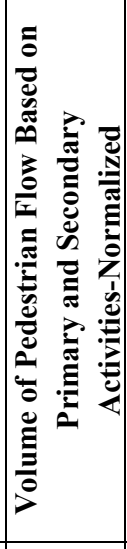 & 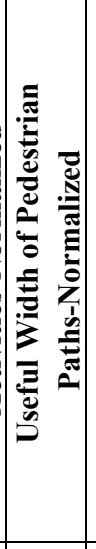 & 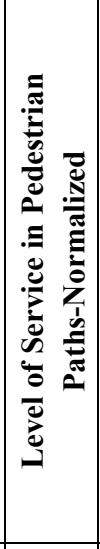 & 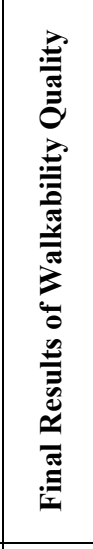 & 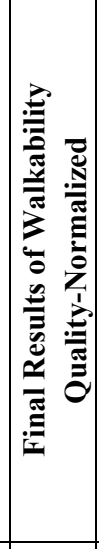 & 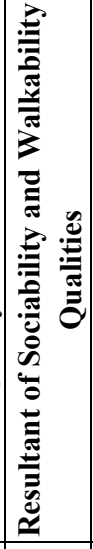 & 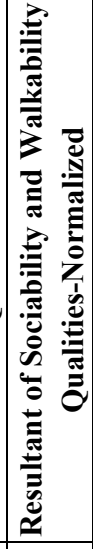 \\
\hline 2 & 0.16 & 0.42 & 0.75 & 1.00 & 1.00 & 0.722 & 1.00 & 0.16 & 1.00 & 1.00 & 0.73 & 0.11 & 1.00 & 1.00 & 0.660 & 1.00 & 1.00 & 1.00 \\
\hline 3 & 0.61 & 0.75 & 0.00 & 0.23 & 0.48 & 0.394 & 0.55 & 0.03 & 0.82 & 0.78 & 0.78 & 0.02 & 0.15 & 0.74 & 0.420 & 0.64 & 0.59 & 0.54 \\
\hline 4 & 0.74 & 0.45 & 0.00 & 0.29 & 0.35 & 0.366 & 0.51 & 0.72 & 0.45 & 0.70 & 0.42 & 0.55 & 0.00 & 0.00 & 0.411 & 0.62 & 0.56 & 0.51 \\
\hline 85 & 0.65 & 0.42 & 0.00 & 0.17 & 0.55 & 0.358 & 0.50 & 0.00 & 0.64 & 0.78 & 0.83 & 0.00 & 0.13 & 0.74 & 0.392 & 0.59 & 0.54 & 0.49 \\
\hline $2-85$ & 0.74 & 0.52 & 0.33 & 0.57 & 1.00 & 0.658 & 1.00 & 0.74 & 0.70 & 0.81 & 0.48 & 0.51 & 0.10 & 0.08 & 0.479 & 0.60 & 0.80 & 0.87 \\
\hline 85-4 & 0.7 & 0.53 & 0.00 & 0.1 & 0.31 & 0.334 & 0.51 & 0.78 & 0.20 & 0.84 & 0.33 & 0.69 & 0.07 & 0.00 & 0.442 & 0.55 & 0.53 & 0.57 \\
\hline 4- & 0.94 & 0.49 & 0.00 & 0.25 & 0.43 & 0.417 & 0.63 & 0.94 & 1.00 & 0.87 & 0.67 & 0.63 & 0.65 & 0.73 & 0.776 & 0.96 & 0.80 & 0.87 \\
\hline & & 0.1 & & 0.44 & 0.73 & & 0.6 & .1 & 1.00 & 1.00 & & .1 & 0.54 & 0.78 & & 0.69 & 0.65 & 0.70 \\
\hline
\end{tabular}

Table 4. Results from the analysis of the level of social capital in a number of nodes and links

\begin{tabular}{|c|c|c|c|c|c|c|c|c|c|c|c|c|c|c|c|c|c|c|c|c|}
\hline Importance & & 0.108 & & 0.22 & & 0.098 & & 0.098 & & 0.125 & & 0.079 & & 0.079 & & 0.079 & & 0.114 & Result & \\
\hline 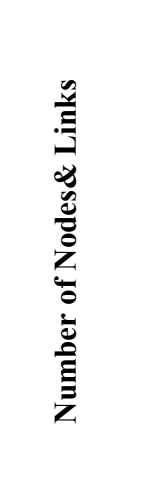 & $\stackrel{\bar{n}}{E}$ & 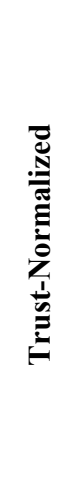 & 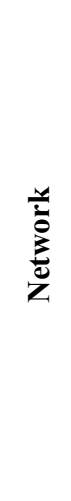 & 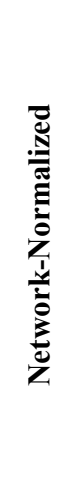 & 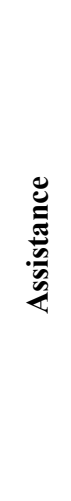 & 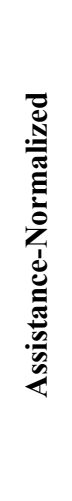 & 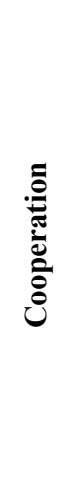 & 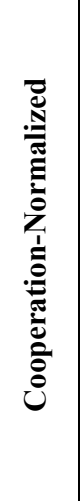 & 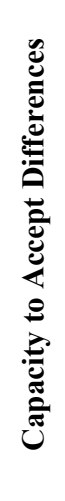 & 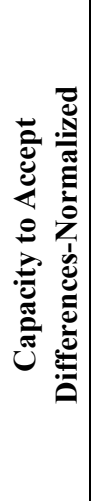 & 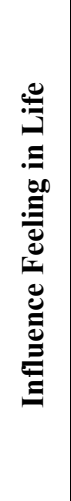 & 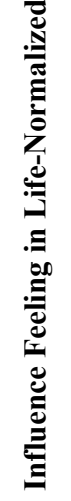 & 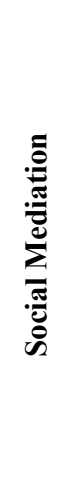 & 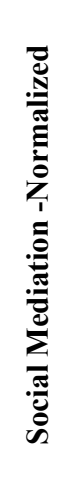 & 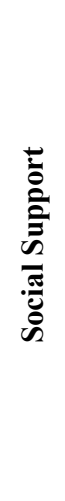 & 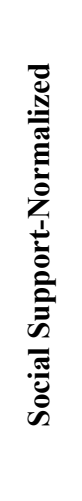 & 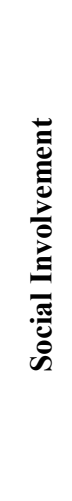 & 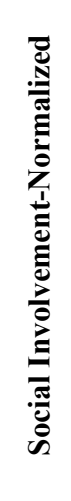 & 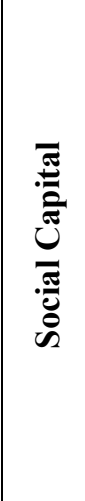 & 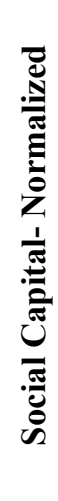 \\
\hline 2 & 31.30 & 0.97 & 12.30 & 0.92 & 10.20 & 0.93 & 4.80 & 0.85 & 5.00 & 0.91 & 2.20 & 0.73 & 2.30 & 0.77 & 4.50 & 0.86 & 10.10 & 0.84 & 0.877 & 1.00 \\
\hline 3 & 32.00 & 0.99 & 10.75 & 0.81 & 11.00 & 1.00 & 5.25 & 0.93 & 4.25 & 0.77 & 2.00 & 0.67 & 2.50 & 0.83 & 4.75 & 0.90 & 9.75 & 0.81 & 0.852 & 0.96 \\
\hline 4 & 28.75 & 0.89 & 11.00 & 0.83 & 9.75 & 0.89 & 4.75 & 0.84 & 4.25 & 0.77 & 2.25 & 0.75 & 2.25 & 0.75 & 5.25 & 1.00 & 11.25 & 0.94 & 0.848 & 0.95 \\
\hline 85 & 31.33 & 0.97 & 10.00 & 0.75 & 10.33 & 0.94 & 5.00 & 0.88 & 5.00 & 0.91 & 2.00 & 0.67 & 1.67 & 0.56 & 5.00 & 0.95 & 12.00 & 1.00 & 0.848 & 0.95 \\
\hline $2-85$ & 63.47 & 0.98 & 23.47 & 0.94 & 20.70 & 0.96 & 9.30 & 0.83 & 9.17 & 0.80 & 4.20 & 0.68 & 4.30 & 0.70 & 9.33 & 0.88 & 21.43 & 0.91 & 0.871 & 0.98 \\
\hline $85-4$ & 61.92 & 0.94 & 22.25 & 0.88 & 19.67 & 0.88 & 8.25 & 0.73 & 9.42 & 0.83 & 3.67 & 0.54 & 4.58 & 0.76 & 8.83 & 0.81 & 18.58 & 0.74 & 0.809 & 0.91 \\
\hline 4-3 & 61.97 & 0.94 & 24.52 & 1.00 & 19.87 & 0.90 & 9.47 & 0.85 & 9.78 & 0.89 & 4.42 & 0.73 & 4.63 & 0.77 & 8.94 & 0.82 & 19.88 & 0.82 & 0.881 & 0.99 \\
\hline 3-2 & 63.67 & 0.99 & 20.00 & 0.76 & 20.33 & 0.93 & 10.33 & 0.94 & 8.33 & 0.67 & 4.33 & 0.71 & 4.67 & 0.78 & 9.00 & 0.83 & 23.00 & 1.00 & 0.839 & 0.94 \\
\hline
\end{tabular}


Table 5. Results from calculating the resultant of walkability and sociability qualities as well as social capital in the nodes

\begin{tabular}{|c|c|c|c|c|c|c|c|c|c|c|c|c|c|c|}
\hline 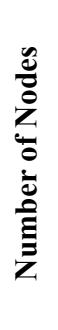 & 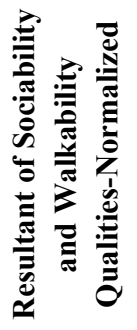 & 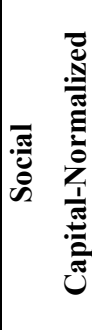 & 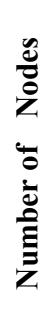 & 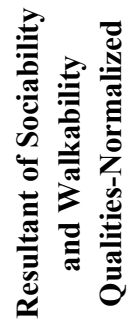 & 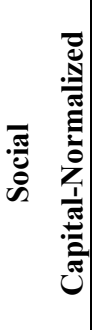 & 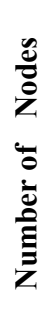 & 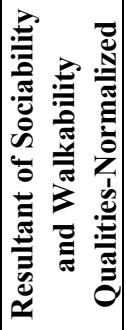 & 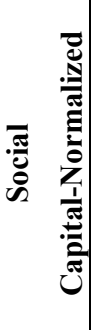 & 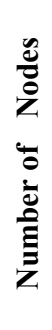 & 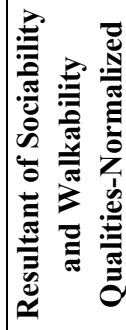 & 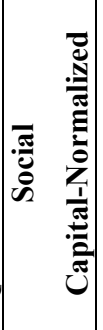 & 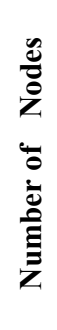 & 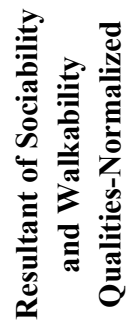 & 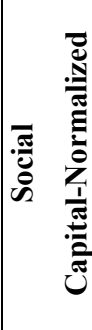 \\
\hline 1 & 0.21 & 0.51 & 20 & 0.21 & 0.46 & 38 & 0.34 & 0.80 & 56 & 0.24 & 0.54 & 74 & 0.08 & 0.10 \\
\hline 2 & 1.00 & 1.00 & 21 & 0.17 & 0.28 & 39 & 0.50 & 0.95 & 57 & 0.32 & 0.76 & 75 & 0.05 & 0.08 \\
\hline 3 & 0.54 & 0.96 & 22 & 0.16 & 0.25 & 40 & 0.43 & 0.93 & 58 & 0.39 & 0.91 & 76 & 0.05 & 0.07 \\
\hline 4 & 0.51 & 0.95 & 23 & 0.36 & 0.86 & 41 & 0.28 & 0.72 & 59 & 0.23 & 0.53 & 77 & 0.34 & 0.81 \\
\hline 5 & 0.19 & 0.31 & 24 & 0.38 & 0.88 & 42 & 0.25 & 0.59 & 60 & 0.07 & 0.09 & 78 & 0.14 & 0.22 \\
\hline 6 & 0.29 & 0.72 & 25 & 0.30 & 0.73 & 43 & 0.24 & 0.57 & 61 & 0.26 & 0.64 & 79 & 0.39 & 0.88 \\
\hline 7 & 0.60 & 0.98 & 26 & 0.35 & 0.82 & 44 & 0.13 & 0.19 & 62 & 0.36 & 0.85 & 80 & 0.32 & 0.76 \\
\hline 8 & 0.89 & 0.99 & 27 & 0.28 & 0.70 & 45 & 0.26 & 0.62 & 63 & 0.09 & 0.13 & 81 & 0.35 & 0.82 \\
\hline 9 & 0.20 & 0.44 & 28 & 0.29 & 0.72 & 46 & 0.70 & 0.99 & 64 & 0.00 & 0.00 & 82 & 0.32 & 0.75 \\
\hline 10 & 0.34 & 0.81 & 29 & 0.38 & 0.86 & 47 & 0.27 & 0.65 & 65 & 0.33 & 0.78 & 83 & 0.30 & 0.74 \\
\hline 11 & 0.34 & 0.81 & 30 & 0.35 & 0.83 & 48 & 0.74 & 0.99 & 66 & 0.15 & 0.23 & 84 & 0.25 & 0.58 \\
\hline 12 & 0.20 & 0.38 & 31 & 0.42 & 0.93 & 49 & 0.20 & 0.42 & 67 & 0.41 & 0.93 & 85 & 0.49 & 0.95 \\
\hline 14 & 0.17 & 0.27 & 32 & 0.31 & 0.75 & $\mathbf{5 0}$ & 0.12 & 0.17 & 68 & 0.59 & 0.97 & 86 & 0.11 & 0.16 \\
\hline 15 & 0.23 & 0.54 & 33 & 0.24 & 0.55 & 51 & 0.11 & 0.14 & 69 & 0.23 & 0.53 & 87 & 0.17 & 0.28 \\
\hline 16 & 0.08 & 0.10 & 34 & 0.30 & 0.74 & 52 & 0.16 & 0.25 & 70 & 0.41 & 0.91 & & & \\
\hline 17 & 0.18 & 0.30 & 35 & 0.26 & 0.61 & 53 & 0.31 & 0.75 & 71 & 0.19 & 0.30 & & & \\
\hline 18 & 0.18 & 0.29 & 36 & 0.22 & 0.51 & 54 & 0.47 & 0.94 & 72 & 0.36 & 0.85 & & & \\
\hline 19 & 0.18 & 0.30 & 37 & 0.45 & 0.93 & 55 & 0.11 & 0.17 & 73 & 0.19 & 0.36 & & & \\
\hline
\end{tabular}


Table 6. Results from calculating the resultant of walkability and sociability qualities as well as social capital in the links

\begin{tabular}{|c|c|c|c|c|c|c|c|c|c|c|c|c|c|c|}
\hline 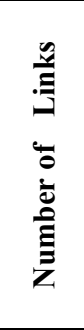 & 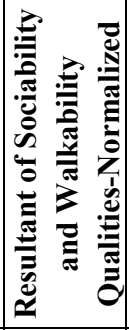 & 量 & 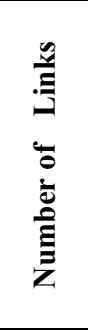 & 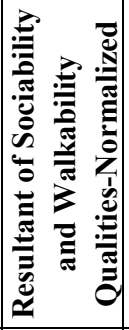 & ש & 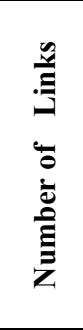 & 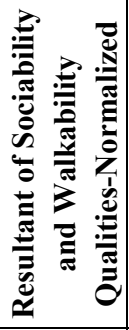 & م & 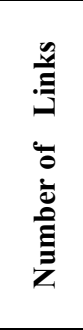 & 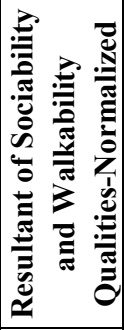 & & 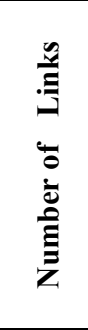 & 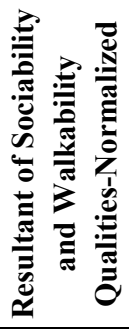 & \\
\hline $60-66$ & 0.34 & 0.54 & $10-77$ & 0.35 & 0.55 & $68-67$ & 0.44 & 0.87 & $30-26$ & 0.43 & 0.86 & 53-65 & 0.38 & 0.76 \\
\hline $66-51$ & 0.35 & 0.57 & $10-11$ & 0.31 & 0.16 & $68-87$ & 0.45 & 0.87 & $31-24$ & 0.31 & 0.22 & $65-83$ & 0.35 & 0.60 \\
\hline $60-73$ & 0.35 & 0.57 & $10-9$ & 0.32 & 0.25 & $68-69$ & 0.38 & 0.75 & 23-32 & 0.35 & 0.60 & 83-58 & 0.36 & 0.66 \\
\hline $73-67$ & 0.36 & 0.69 & $9-6$ & 0.59 & 0.92 & $68-70$ & 0.60 & 0.92 & 23-33 & 0.35 & 0.61 & 65-61 & 0.34 & 0.43 \\
\hline $67-66$ & 0.32 & 0.31 & $6-7$ & 0.68 & 0.90 & $68-50$ & 0.44 & 0.87 & $32-34$ & 0.37 & 0.73 & 65-59 & 0.32 & 0.32 \\
\hline $73-74$ & 0.36 & 0.70 & $7-8$ & 1.00 & 1.00 & $50-69$ & 0.39 & 0.84 & 31-32 & 0.36 & 0.65 & $83-61$ & 0.32 & 0.30 \\
\hline $74-71$ & 0.41 & 0.83 & 8-3 & 0.80 & 0.97 & $69-49$ & 0.43 & 0.85 & 31-34 & 0.33 & 0.42 & 83-59 & 0.33 & 0.42 \\
\hline $74-76$ & 0.31 & 0.16 & $4-5$ & 0.69 & 0.96 & $49-87$ & 0.36 & 0.66 & 34-35 & 0.34 & 0.45 & $59-61$ & 0.32 & 0.26 \\
\hline $76-75$ & 0.38 & 0.77 & $5-6$ & 0.52 & 0.90 & $87-51$ & 0.30 & 0.14 & $35-36$ & 0.34 & 0.53 & $59-58$ & 0.34 & 0.47 \\
\hline $75-72$ & 0.33 & 0.43 & $5-17$ & 0.40 & 0.80 & $17-18$ & 0.39 & 0.79 & $36-38$ & 0.35 & 0.56 & $58-57$ & 0.41 & 0.84 \\
\hline $72-77$ & 0.33 & 0.34 & $17-6$ & 0.41 & 0.78 & $18-84$ & 0.37 & 0.70 & 38-37 & 0.33 & 0.38 & $57-82$ & 0.34 & 0.52 \\
\hline $75-71$ & 0.41 & 0.84 & $6-41$ & 0.52 & 0.90 & 18-19 & 0.35 & 0.64 & $29-37$ & 0.35 & 0.58 & 33-82 & 0.32 & 0.28 \\
\hline $71-12$ & 0.38 & 0.77 & $41-40$ & 0.32 & 0.26 & $19-84$ & 0.34 & 0.48 & 37-39 & 0.40 & 0.81 & $33-58$ & 0.36 & 0.68 \\
\hline $77-71$ & 0.34 & 0.52 & $41-42$ & 0.37 & 0.72 & 84-28 & 0.33 & 0.42 & 28-37 & 0.32 & 0.30 & $57-56$ & 0.35 & 0.55 \\
\hline 11-12 & 0.30 & 0.13 & $42-9$ & 0.38 & 0.76 & $19-20$ & 0.32 & 0.25 & $37-84$ & 0.33 & 0.42 & $56-59$ & 0.36 & 0.69 \\
\hline $12-14$ & 0.34 & 0.47 & $42-43$ & 0.38 & 0.77 & 20-27 & 0.37 & 0.74 & $84-40$ & 0.35 & 0.59 & $56-55$ & 0.39 & 0.78 \\
\hline 14-1 & 0.65 & 0.92 & $43-44$ & 0.36 & 0.70 & $20-21$ & 0.32 & 0.32 & 40-39 & 0.34 & 0.53 & $55-86$ & 0.34 & 0.53 \\
\hline $1-2$ & 0.82 & 0.97 & $43-45$ & 0.36 & 0.68 & $21-22$ & 0.35 & 0.60 & $39-80$ & 0.41 & 0.82 & $86-52$ & 0.37 & 0.75 \\
\hline $2-85$ & 0.87 & 0.98 & $45-50$ & 0.43 & 0.86 & $22-23$ & 0.40 & 0.80 & $40-45$ & 0.37 & 0.71 & $59-86$ & 0.39 & 0.78 \\
\hline $1-85$ & 0.79 & 0.93 & 44-9 & 0.45 & 0.87 & 23-24 & 0.31 & 0.23 & $40-80$ & 0.37 & 0.70 & $52-61$ & 0.38 & 0.76 \\
\hline $85-4$ & 0.57 & 0.91 & 44-77 & 0.34 & 0.48 & $24-25$ & 0.34 & 0.52 & $80-54$ & 0.41 & 0.84 & $61-62$ & 0.37 & 0.74 \\
\hline 4-3 & 0.87 & 0.99 & $44-72$ & 0.32 & 0.31 & $25-21$ & 0.36 & 0.68 & $54-45$ & 0.32 & 0.30 & $62-63$ & 0.39 & 0.79 \\
\hline 3-2 & 0.70 & 0.94 & $72-79$ & 0.29 & 0.08 & $25-26$ & 0.48 & 0.88 & $45-46$ & 0.53 & 0.91 & 63-52 & 0.33 & 0.35 \\
\hline $2-1$ & 0.79 & 0.96 & $79-78$ & 0.35 & 0.61 & $26-27$ & 0.39 & 0.78 & 54-46 & 0.74 & 0.95 & $63-64$ & 0.34 & 0.52 \\
\hline $2-15$ & 0.72 & 0.95 & $44-78$ & 0.42 & 0.84 & $27-28$ & 0.36 & 0.66 & 54-38 & 0.35 & 0.58 & $64-51$ & 0.38 & 0.75 \\
\hline $15-14$ & 0.30 & 0.14 & $78-50$ & 0.44 & 0.87 & 28-29 & 0.35 & 0.59 & 46-81 & 0.43 & 0.87 & $51-49$ & 0.39 & 0.79 \\
\hline $15-16$ & 0.32 & 0.23 & $79-70$ & 0.35 & 0.64 & $28-30$ & 0.35 & 0.57 & $81-36$ & 0.40 & 0.82 & $49-47$ & 0.38 & 0.78 \\
\hline $16-11$ & 0.32 & 0.27 & $70-76$ & 0.36 & 0.70 & $30-29$ & 0.35 & 0.58 & $81-48$ & 0.52 & 0.93 & $47-46$ & 0.51 & 0.88 \\
\hline $16-7$ & 0.35 & 0.59 & $70-67$ & 0.34 & 0.52 & $29-31$ & 0.35 & 0.56 & $48-53$ & 0.52 & 0.88 & $47-48$ & 0.43 & 0.87 \\
\hline $16-10$ & 0.32 & 0.25 & $67-76$ & 0.34 & 0.50 & $30-31$ & 0.35 & 0.64 & 53-61 & 0.40 & 0.80 & $48-62$ & 0.46 & 0.88 \\
\hline
\end{tabular}




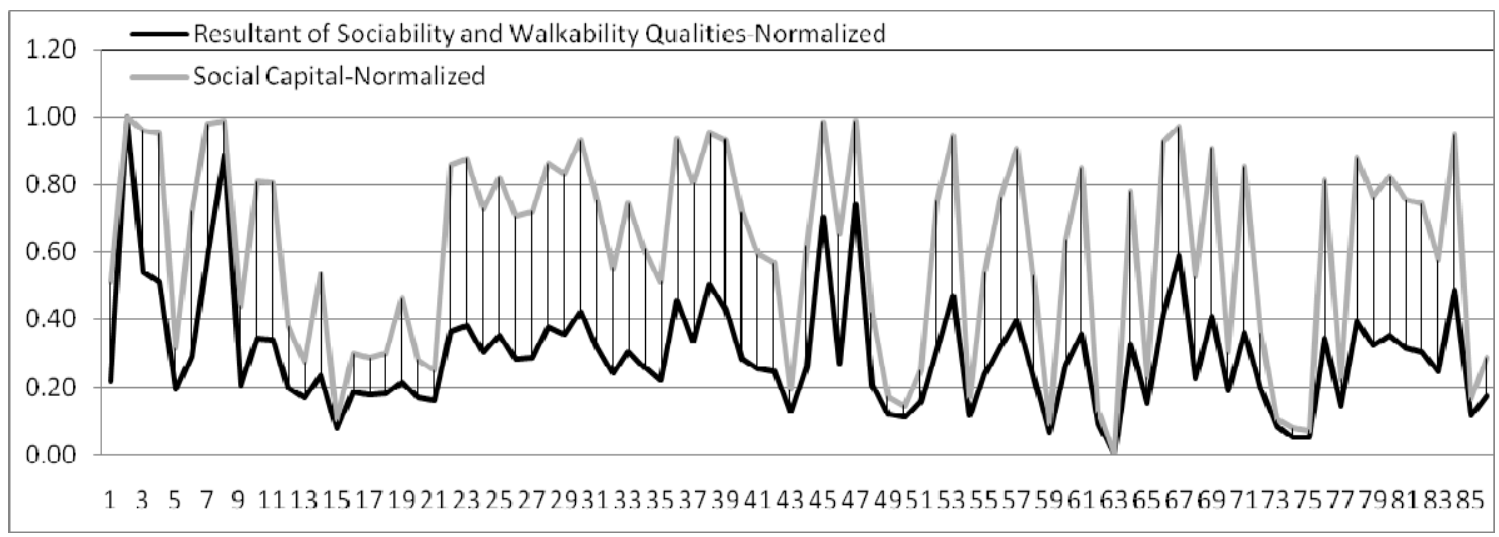

Figure 1. Comparison of the results from calculation of walkability and sociability qualities and social capital in nodes

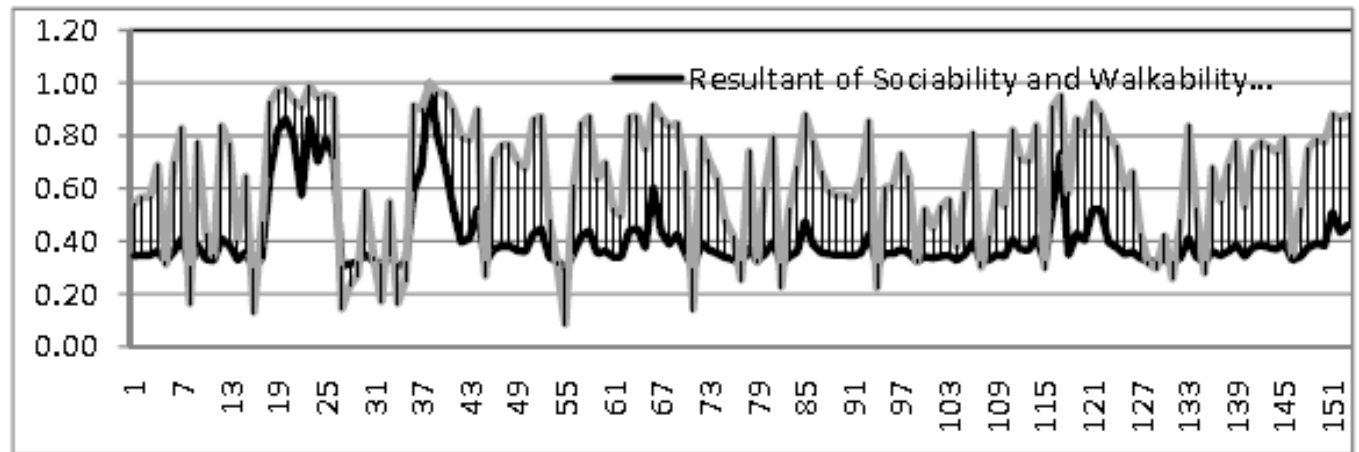

Figure 2. Comparison of the results from calculation of walkability and sociability qualities and social capital in links

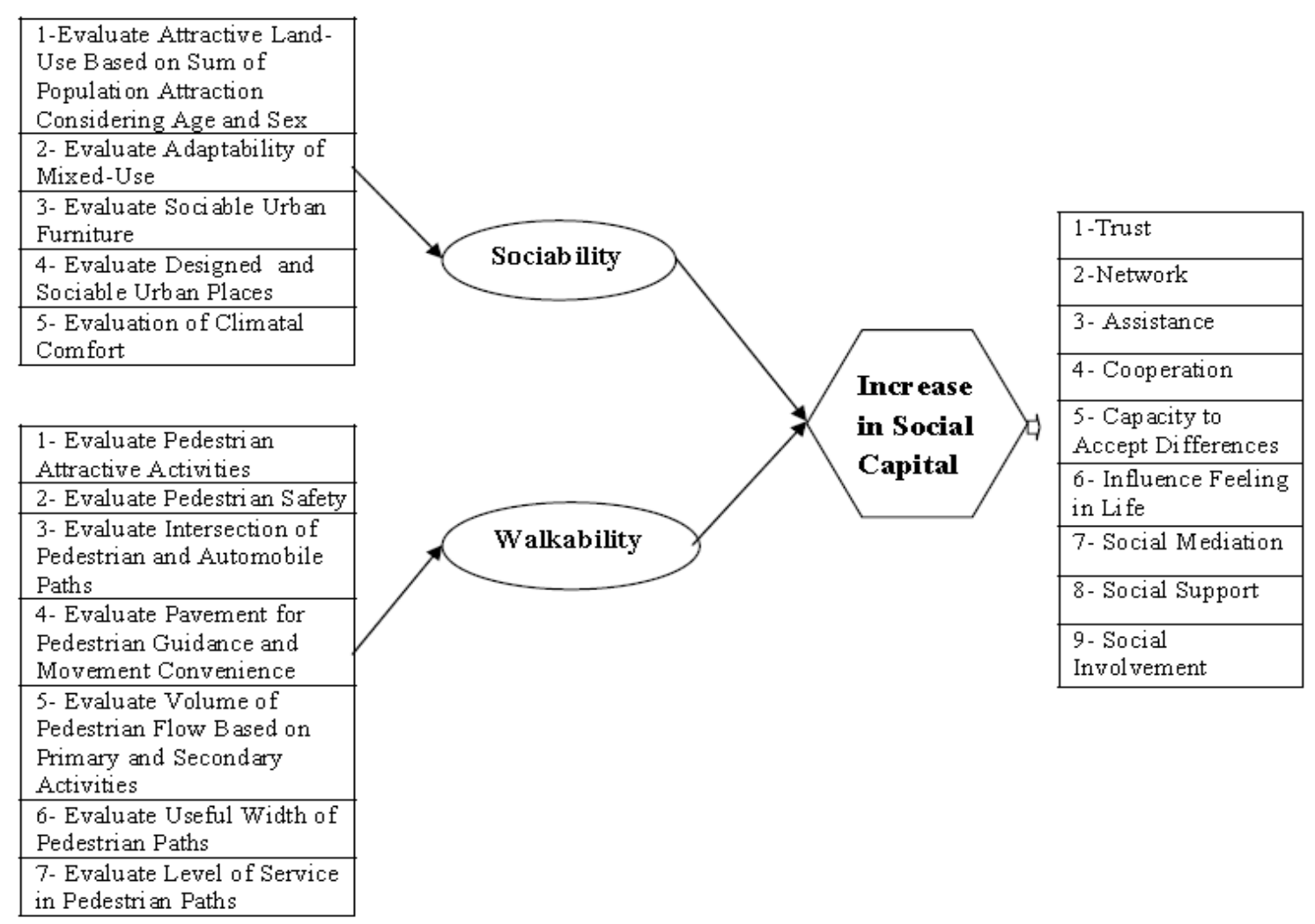

Figure 3. The effect of urban qualities (and sub-qualities) on social capital 


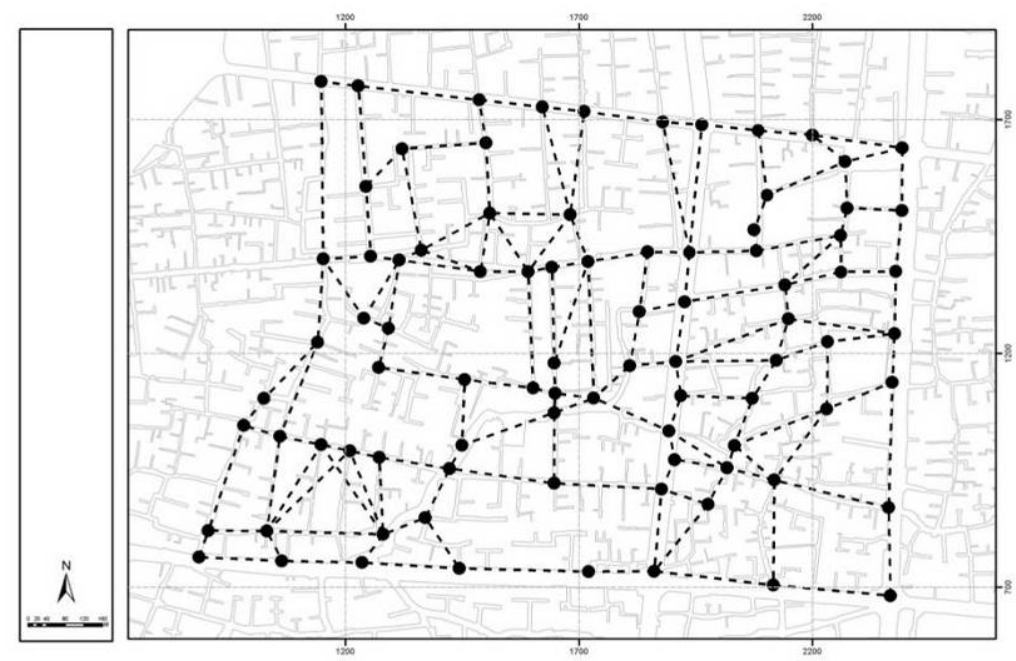

Map 1. Position of social nodes and links connecting them in Jolfa district of Isfahan

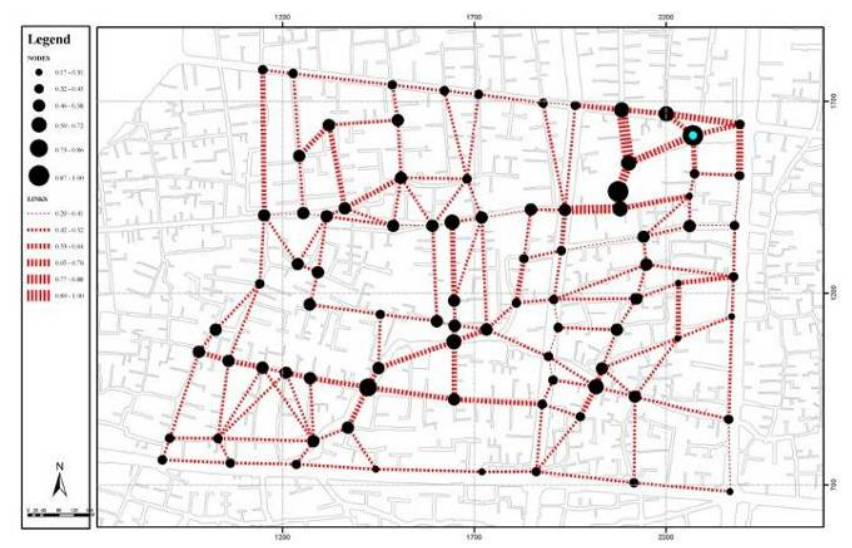

Map 2. Graphical display of comparing the nodes and links of the district in terms of walkability

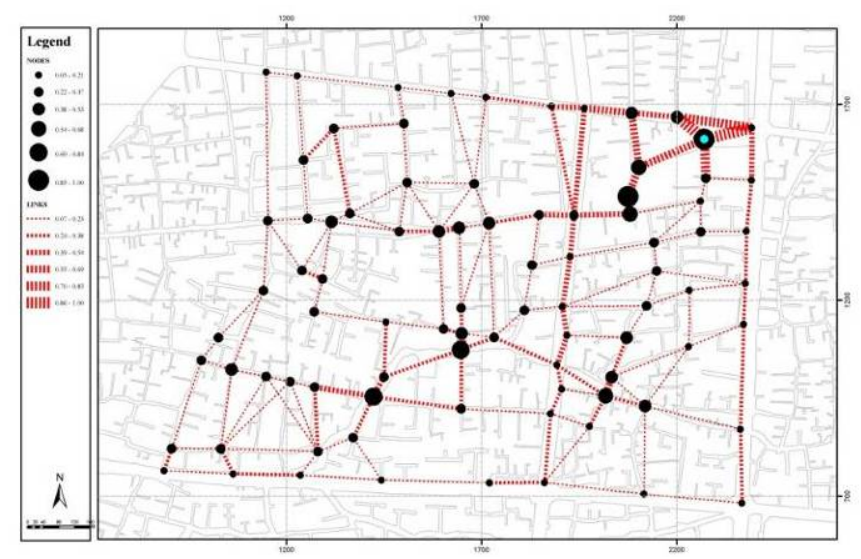

Map 3. Graphical display of comparing the nodes and links of the district in terms of sociability 


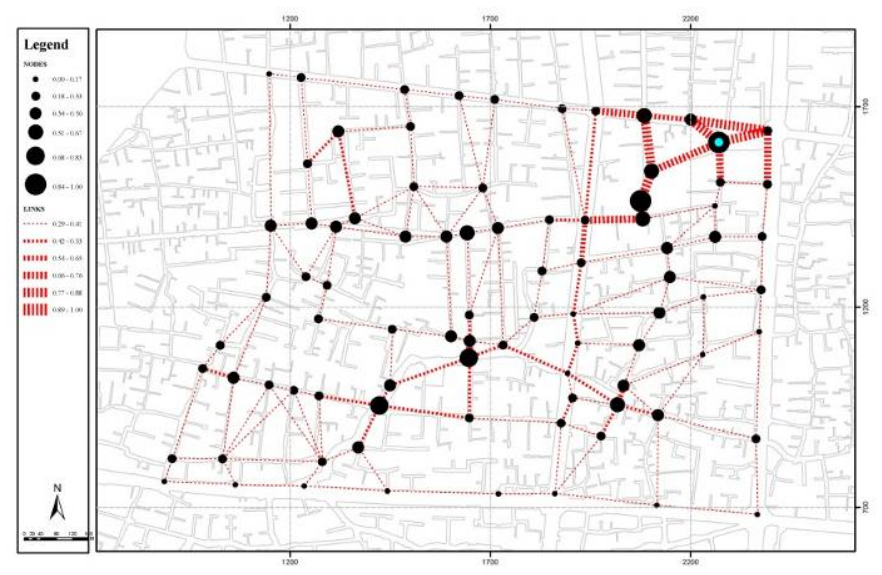

Map 4. Graphical display of comparing the nodes and links of the district in terms of Resultant of walkability and sociability

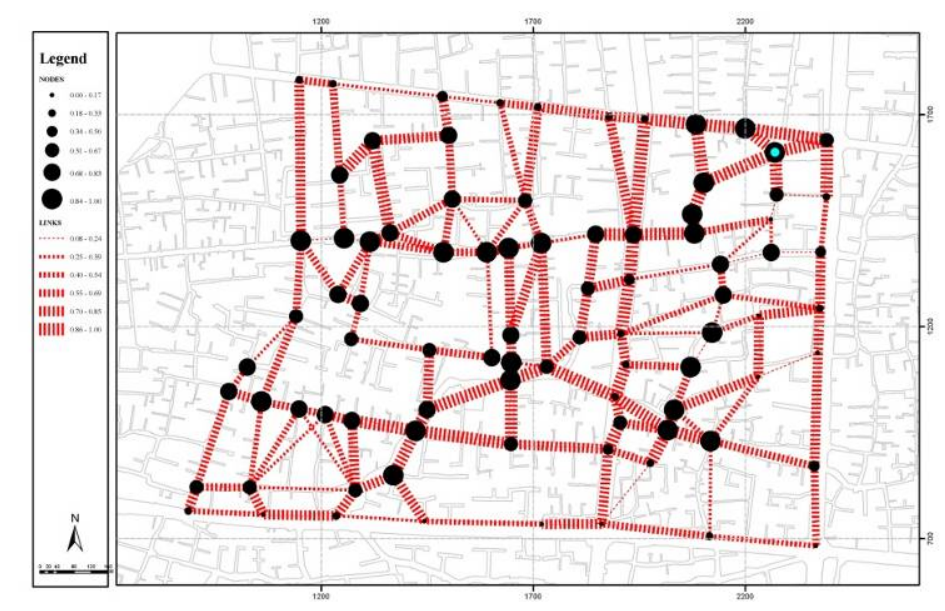

Map 5. Graphical display of the level of social capital in the nodes and links of the district 